\title{
Optimization Design for Detonation Powerplant Based on LS-DYNA Simulation
}

\author{
Yongbao Ai and Ming Lu \\ College of Field Engineering, PLA University of Science and Technology, Nanjing, Jiangsu 210007, China \\ Correspondence should be addressed to Ming Lu; aybjackai@163.com
}

Received 28 February 2016; Revised 11 May 2016; Accepted 30 June 2016

Academic Editor: Michael Vynnycky

Copyright (C) 2016 Y. Ai and M. Lu. This is an open access article distributed under the Creative Commons Attribution License, which permits unrestricted use, distribution, and reproduction in any medium, provided the original work is properly cited.

To ensure the accuracy of the work capacity of the detonation powerplant, the explosive and shock process of detonation powerplants was simulated with LS-DYNA. Many maximum rising displacements of the cartridge indicating the work capacity of the device were obtained, under different fit clearances of the device. It was proved that fit clearances were the key factors affecting the work capacity of the device, and reasonable range for fit clearances was found. Besides, the objective function, constraint condition, and optimization design variables of the Genetic Algorithm were determined according to the design indicators of the detonation powerplant. The theoretical values of fit clearances of the optimization design of detonation powerplants were obtained. At last, the tests of the work capacity of the detonation powerplant and LS-DYNA simulation proved the rationality of the theoretical values from the Genetic Algorithm, providing an experimental proof for the accuracy design, which could control the service door movement accurately.

\section{Introduction}

According to the CCAR-21-R3 "Provisions for the Approval of Civil Aviation Products and Parts" of Civil Aviation Administration of China, enough measures must be taken to safeguard the life safety of the crew in flight tests. The new regional jet independently designed and manufactured by China needs to carry out the test flight in accordance with airworthiness regulations. To make sure that the test flight crew are able to escape from the aircraft in an emergency situation, the multisection telescopic detonation powerplant which is the core device of the emergency escaping support system is made. It is the first case in China where accurate blasting technique is applied to the civil aviation life-saving field [1]. The working principle sketch of the detonation powerplant is shown in Figure 1. Its function is to overcome about $6 \mathrm{KN}$ aerodynamic drag applied on the surface of the service door and push it toward the cabin in certain track and pose through the cooperation of the four sets of devices [2], providing an emergency barrier-free escaping tunnel to the crew. The research and manufacture of detonation powerplants open a new field for civil aviation life-saving. During the movement, the service door needs to keep in certain track and pose.
Namely, the angle of the door's lateral overturning should not be larger than $10^{\circ}$, the movement distance is $2 \mathrm{~m}$, the error is smaller than $15 \%$, and no unacceptable harm to the pose of the aircraft or the crew is caused during the movement. Therefore, to ensure the accuracy of the work capacity of the detonation powerplant and the maximal utilization rate of the gunpowder, simulating the working process of detonation powerplants with LS-DYNA and optimizing the design of parameters through Genetic Algorithm have great meaning.

At the early stage of the research and development of the detonation powerplant, in the work capacity test experiment, it has found that there was great discrepancy in the work capacity of the devices, which does not comply with the technical indicator of the error of the work capacity being less than $10 \%$. As a result, the movement of the service door cannot be controlled accurately. To solve this problem and improve the energy utilization rate of the gunpowder, key factors that influence the work capacity of the detonation powerplant are analyzed and studied [3]. And it is found that the fit clearances inside the device are key factors. The sketch of the detonation powerplant is depicted in Figure 2, including height of the cartridge $H_{1}$, outer diameter $D_{1}$, inner diameter $d_{1}$, and height of the cavity $h_{1}$; height of the slide 


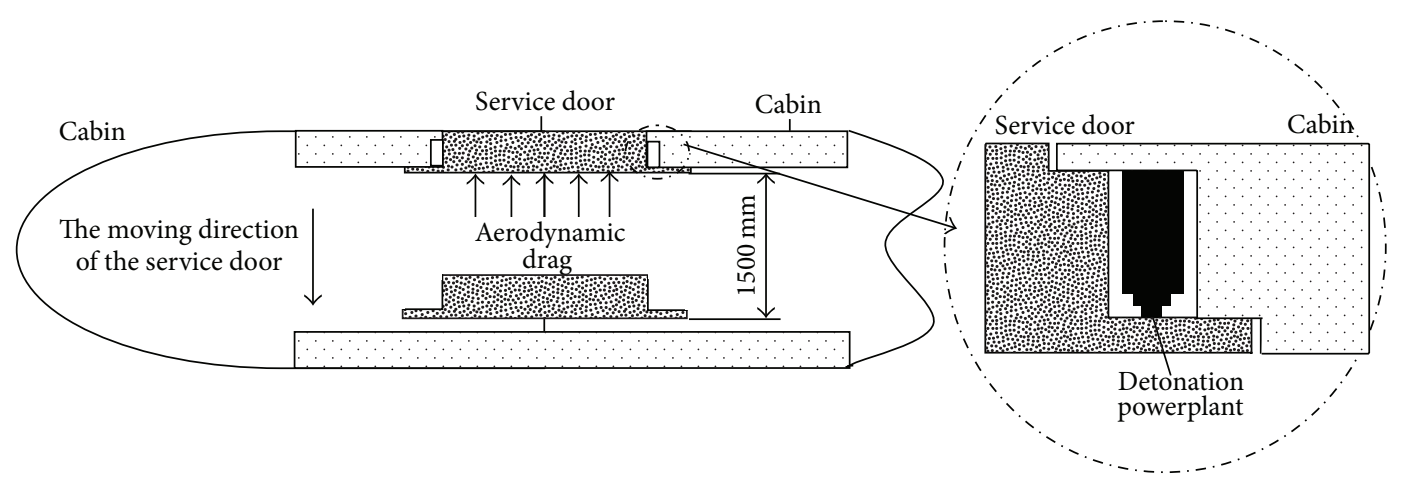

FIGURE 1: Working principle of the detonation powerplant pushing door [2].

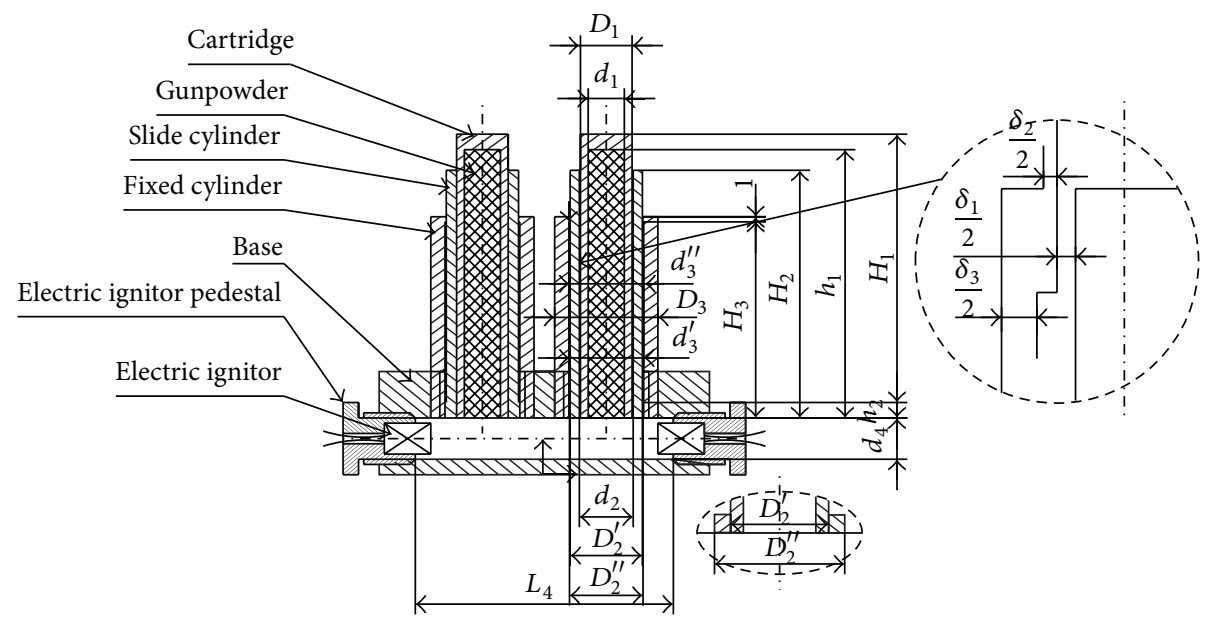

FIGURE 2: Physical model of the detonation powerplant.

cylinder $\mathrm{H}_{2}$, outer wall diameter $D_{2}^{\prime}$, outer lace diameter $D_{2}^{\prime \prime}$, inner diameter $d_{2}$, and height of the outer lace $h_{2}$; height of the fixed cylinder $\mathrm{H}_{3}$, outer diameter $D_{3}$, inner wall diameter $d_{3}^{\prime}$, and inner lace diameter $d_{3}^{\prime \prime}$; length of the cavity inside base $L_{4}$ and diameter $d_{4}$; the fit clearance between the outer wall of the cartridge and the inner wall of the slide cylinder $\delta_{1}$; the fit clearance between the outer wall of the slide cylinder and the lace of the fixed cylinder $\delta_{2}$; the fit clearance between the lace of the slide cylinder and the inner wall of the fixed cylinder $\delta_{3}$.

Through the simulations in Section 2, it is found that the fit clearances between the outer wall of the cartridge and the inner wall of the slide cylinder, the outer wall of the slide cylinder and the lace of the fixed cylinder, and the lace of the slide cylinder and the inner wall of the fixed cylinder are the key factors that affect the accuracy of the work capacity of the detonation powerplant. Besides, the reasonable range of these fit clearances is obtained, which lays a foundation for the next research. Section 3 optimizes the design of the three fit clearances of the detonation powerplant with the Genetic Algorithm [4-6], figures out the law of fit clearances affecting the work capacity of the detonation powerplant and the energy utilization rate of the gunpowder, and at last obtains the theoretical optimal values of the fit clearances. In Section 4, to test the rationality of the values obtained in Section 3, a detonation powerplant work capacity test experiment is carried out and the explosive and shock process of the detonation powerplant is simulated with LSDYNA. Results illustrate that, within an acceptable error range, the work capacity of the detonation powerplant with the theoretical parameters can satisfy the design indicators.

\section{LS-DYNA Simulation}

\subsection{LS-DYNA Modeling and Solution}

2.1.1. Analysis of Modeling. There are mainly two ways to simulate the explosive process, including

(1) Lagrange Algorithm, in which the explosive element is the eight-node entity element. The explosive element and the element exploded could share the same node or could be connected by the contact. The first is relatively faster than the second in computing. 


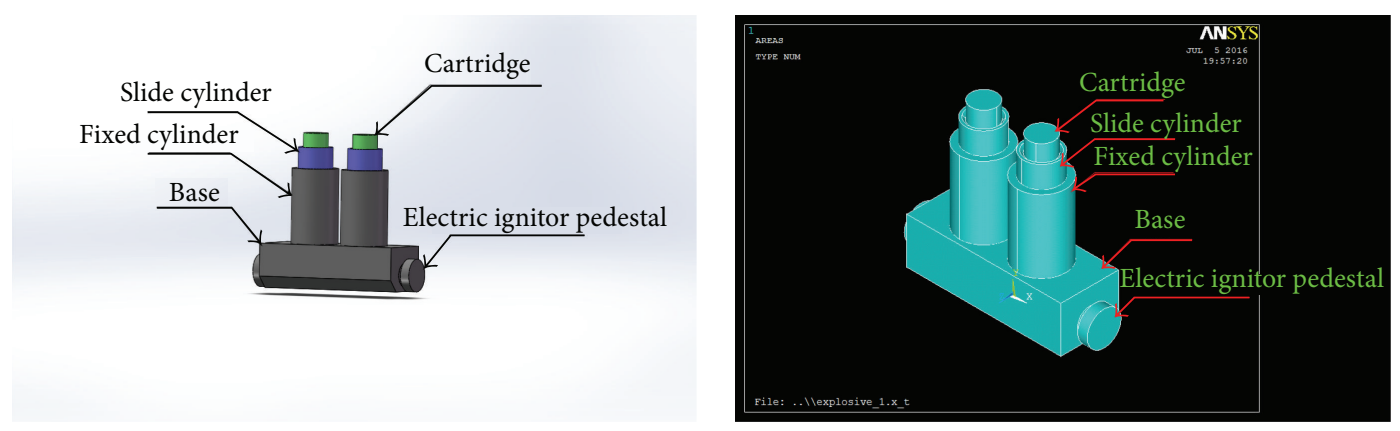

FIGURE 3: 3D model of the detonation powerplant.

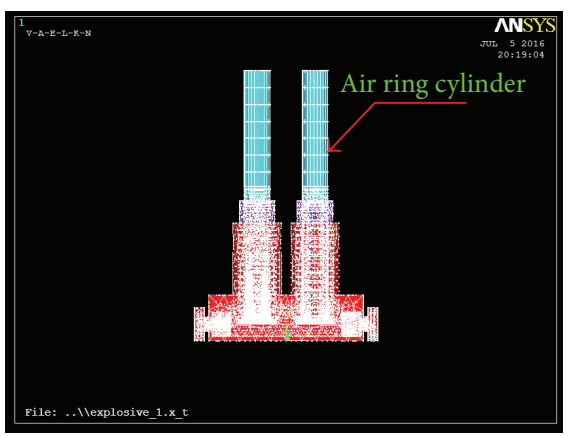

FIgURE 4: The finite element mesh model of the detonation powerplant.

(2) Arbitrary Lagrangian-Eulerian, ALE, in which the explosive element is the Euler element and the element exploded is the Lagrange element. The explosion between the two grids is simulated by the defined coupling [7].

In Lagrange Algorithm, there is a great chance that severe distortion happens to the explosive element, thus stopping the computing process. Therefore, though ALE is slower than Lagrange Algorithm, it can effectively avoid such problems caused by severe distortion of the grids as computational divergence and unreliable computing results.

2.1.2. Model Building. A calculation physics model is built with Solidworks, and then the model is imported in LSDYNA, which is presented in Figure 3. (On the left is the Solidworks 3D model; on the right is the Ansys 3D model.)

The explosive is calculated with Eulerian Algorithm and depicted with MAT_ELASTIC_PLASTIC_HYDEO material model and PROPELLANT_DETONATION equation of state; the air is also calculated with Eulerian Algorithm but depicted with NULL material model and LINEAR_POLYNOMIAL equation of state; the detonation powerplant is calculated with Lagrange Algorithm and depicted with RIGID material model [8-10]. A finite element model is got after meshing, which is shown in Figure 4.

The work done by detonation powerplants in pushing the service door mainly has two parts: (1) work done to overcome the aerodynamic drag on the service door; (2) work done to provide kinetic energy to the service door, which enables the service door to move specified distance in prescribed pose. In

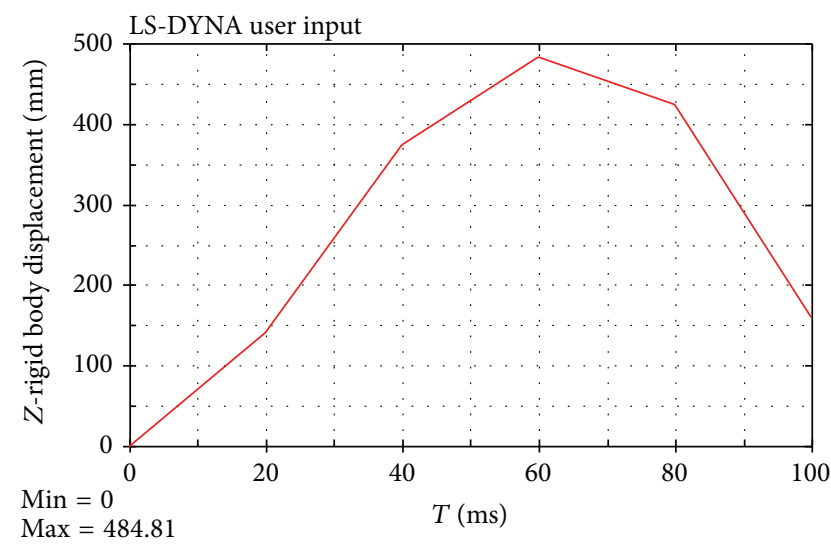

FIGURE 5: $\delta_{1}=0.024, \delta_{2}=0.067$, and $\delta_{3}=0.053 ; T-Z$ curve.

the shock, the cartridges of the detonation powerplant push the service door, doing work to the outside. According to the design of the detonation powerplant work capacity test experiment in Section 4, a load of $0.6 \mathrm{KN}$ is applied in the cartridge to simulate the process.

2.2. Simulation Results and Analyses. Select a set of fit clearances of the cartridge, slide cylinder, and fixed cylinder for designed detonation powerplants; then output the timedisplacement curve of the cartridge with LS-PrePost (see Figure 5). The maximum value of the displacement represents the work capacity of the detonation powerplant. By changing the entity model constantly, simulations of the explosive and 
TABLE 1: Four sets of fit clearances, unit: $\mathrm{mm}$.

\begin{tabular}{lcccccc}
\hline$A$ & \multicolumn{2}{c}{$B$} & \multicolumn{2}{c}{$C$} & \multicolumn{2}{c}{$D$} \\
$\delta_{1}=\delta_{2}=\delta_{3}$ & $\delta_{3}$ & $\delta_{1}=\delta_{2}$ & $\delta_{2}$ & $\delta_{1}=\delta_{3}$ & $\delta_{1}$ & $\delta_{2}=\delta_{3}$ \\
\hline 0.01 & 0.01 & & 0.01 & & 0.01 & \\
0.02 & 0.02 & & 0.02 & & 0.02 & \\
0.03 & 0.03 & & 0.03 & & 0.03 & \\
0.04 & 0.04 & & 0.04 & & 0.04 & \\
0.05 & 0.05 & 0.05 & 0.05 & 0.05 & 0.05 & 0.05 \\
0.06 & 0.06 & & 0.06 & & 0.06 & \\
0.07 & 0.07 & & 0.07 & & 0.07 & \\
0.08 & 0.08 & & 0.08 & & 0.08 & \\
0.09 & 0.09 & & 0.09 & & 0.09 & \\
0.10 & 0.10 & & 0.10 & & 0.10 & \\
\hline
\end{tabular}

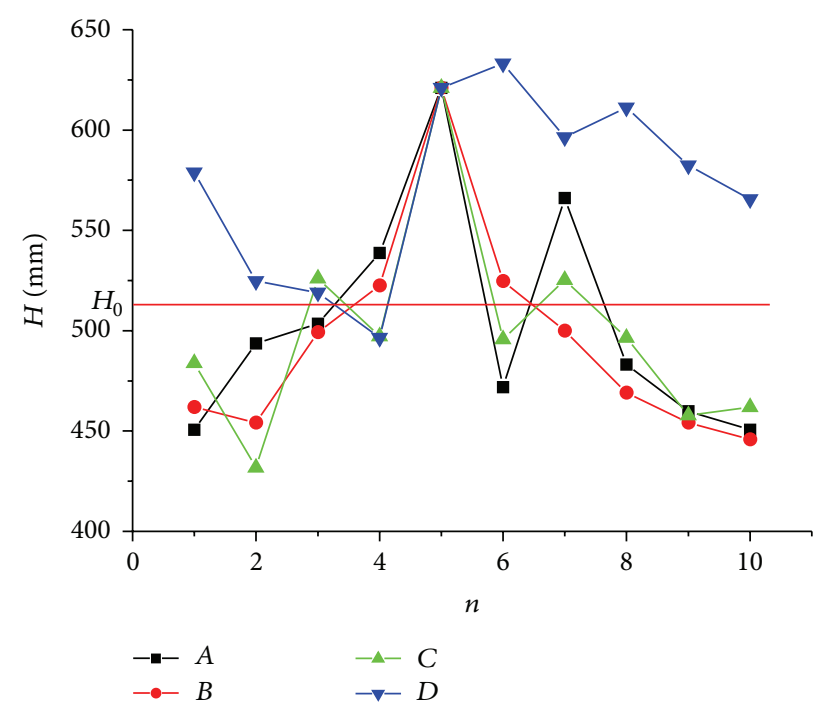

FIGURE 6: Variation curve of 40 sets maximum displacements of the cartridge in accordance with different clearance parameters.

shock process of the detonation powerplant with different fit clearances (Table 1) can be realized. As a result, a series of effective data are obtained, with which wave curves are drawn in Figure 6. Figure 6 shows that, under different fit clearances, maximum displacements of cartridge indicating the work capacity of the detonation powerplant are different. This illustrates that the fit clearances of the detonation powerplant are the key factors affecting the work capacity of the device and the energy utilization rate of the gunpowder. After early design, it is clear that the work capacity needs to reach $302.75 \mathrm{~J}$. By taking the mass of the weight in Section $4 M=$ $60 \mathrm{~kg}$ into the formula $W=\mathrm{MgH}$, the most appropriate lifting height of the weight can be known $H_{0}=514.9 \mathrm{~mm}$. In Figure 6, the height $H_{0}$ is represented by the straight line parallel to the $x$-axis. On the basis of fluctuations of curve $A$, $B, C$ and $D$ near the line $H_{0}$, reasonable range of the three fit clearances can be determined. That is, $0.02 \mathrm{~mm} \leq \delta_{1} \leq$ $0.05 \mathrm{~mm}, 0.03 \mathrm{~mm} \leq \delta_{2}, \delta_{3} \leq 0.07 \mathrm{~mm}$.

\section{Optimization Design of Internal Ballistics Parameters with Genetic Algorithm}

3.1. Basic Hypothesis. The internal ballistics zero dimension mathematical model of the detonation powerplant is a space averaging parameter model based on Lagrange hypothesis [11]. On the basis of internal ballistics theory and practical situation of the detonation powerplant, hypotheses as below have been made [12]: (1) The burning of gunpowder follows the geometry burning rule. (2) The burning of gunpowder particles follows the burning velocity rule. (3) Gunpowder gas equation of state complies with the Nobel-Abel equation. (4) Leave out the gas pressure gradient in the cavity of the detonation powerplant. (5) Ingredients produced in the burning of gunpowder remain the same. (6) The loss of heat is corrected by decreasing gunpowder impetus $f$ or increasing ratio of specific heat $k$. (7) Ignore the influence of assistant gunpowder charge on the performance of the detonation powerplant internal ballistics. (8) Ignore the influence of electric igniters on the performance of the detonation powerplant at the moment of ignition.

3.2. Determination of Objective Function. In this section, the mathematical equations of the optimization design of the detonation powerplant internal ballistics parameters are built and the optimization design of internal ballistics is carried out, so that the design cycle is shortened and the design quality is improved. The process of the detonation powerplant doing work to outside can be divided into four stages. On the basis of the characteristic of each stage and classic ballistic theories such as internal ballistics gunpowder gas equation of state, burning equation, energy conservation law, and kinematic equation [13-17], the mathematical models of internal ballistics of the four stages are built.

The first stage is the period from the ignition of gunpowder to the time when the cartridge and slide cylinder start to move. In this period, the gunpowder is burning in constant volume and the gas pressure in the cavity produced by the burning of gunpowder gradually increases from zero to start pressure. The constant volume equation of state, gunpowder shape function, Euler equation which represents the onedimensional linear motion of the gas in device [18], and relative gas leakage flow of this period are

$$
\begin{aligned}
& \Psi=\frac{1 / \Delta-1 / \rho_{p}}{f / p_{0}+\alpha-1 / \rho_{p}}, \\
& \Psi=\chi Z(1+\lambda Z), \\
& \frac{\partial \rho}{\partial t}+\frac{\partial(\rho Q)}{\partial z}=0, \\
& \frac{\partial(\rho Q)}{\partial t}+\frac{\partial\left(\rho Q^{2}\right)}{\partial z}=\rho f_{z}-\frac{\partial p}{\partial z}, \\
& \frac{\partial}{\partial t}(\rho E)+\frac{\partial}{\partial z}(\rho E Q)=\rho q-\frac{\partial(Q p)}{\partial z}+\rho Q f_{z},
\end{aligned}
$$




$$
\begin{aligned}
\eta & =\frac{y}{\omega}=\frac{\left(A_{1}+A_{2}+A_{3}\right) Q t}{\omega} \\
& =\frac{\pi t\left[\left(d_{1}+\delta_{1}\right) \delta_{1}+\left(d_{2}+\delta_{2}\right) \delta_{2}+\left(d_{3}-\delta_{3}\right) \delta_{3}\right]}{\omega} .
\end{aligned}
$$

The second stage is the period from the time when the cartridge and slide cylinder start to move to the time when the gunpowder burns out. In this period, the cartridge and slide cylinder move along the axis of the fixed cylinder. When the gunpowder burns out, the gas pressure in the cavity reaches the maximum. The power state function, gunpowder burning equation, equation of the movement of the cartridge and slide cylinder, the kinematical equation that calculates the speed and distance of cartridge's and slide cylinder's movement, and relative gas leakage flow of this period are

$$
\begin{aligned}
\Psi & =\chi Z(1+\lambda Z), \\
\frac{d Z}{d t} & =\frac{\mu_{1} p^{n}}{e_{1}}=\frac{p^{n}}{I_{k}}, \\
S_{2} p & =\varphi m \frac{d v}{d t}, \\
v & =\frac{d l}{d t}, \\
S_{2} p\left(l_{\Psi}+l\right) & =f \omega(\Psi-\eta)-(k-1) \varphi \frac{m v^{2}}{2}, \\
\eta & =\frac{y}{\omega}=\frac{\left(A_{1}+A_{2}+A_{3}\right) Q t}{\omega} .
\end{aligned}
$$

The third stage is the period from the time when the gunpowder burns out to the time when the slide cylinder's movement stops. In this period, the gas of high temperature and pressure continues to expand and do work to outside, pushing the cartridge and slide cylinder to move. Meanwhile, the gas pressure inside the cavity starts to drop. After the slide cylinder moves for a distance, its lower lace strikes the upper lace of the fixed cylinder and it is stopped. The kinematical equation of the movement of the cartridge and slide cylinder, energy equation, and relative gas leakage flow of this period are

$$
\begin{aligned}
S_{2} p & =\varphi m \frac{d v}{d t}, \\
S_{2} p\left(l_{1}+l\right) & =f \omega(1-\eta)-\frac{(k-1)}{2 \varphi m v^{2}}, \\
\eta & =\frac{y}{\omega}=\frac{\left(A_{1}+A_{2}+A_{3}\right) Q t}{\omega} .
\end{aligned}
$$

The fourth stage is the period from the time when the movement of the slide cartridge stops to the time when the cartridge separates from the slide cylinder. In this period, though the pressure of the gas keeps dropping, it continues to expand and push the cartridge to move along the inner wall of the slide cylinder. Then the process of doing work finishes until the cartridge separates from the slide cylinder. The kinematical equation of the movement of the cartridge, the energy equation, and relative gas leakage flow of this period are

$$
\begin{aligned}
S_{1} p & =\varphi m \frac{d v}{d t} \\
S_{1} p\left(l_{1}+l\right) & =f \omega(1-\eta)-\frac{(k-1)}{2 \varphi m v^{2}} \\
\eta & =\frac{y}{\omega}=\frac{A_{1} Q t}{\omega} .
\end{aligned}
$$

Later, the service door stops accelerating and gets an initial velocity; then it starts flat parabolic motion. When the service door touches the floor of the cabin, it starts to spin around the horizontal centroidal axis and continues to lose speed until the speed reduces to zero. Then the service door falls on the floor. The energy equation that transforms the process above into the working process of devices in the detonation powerplant work capacity test experiment is

$$
W=M g H=E_{\max }=m v_{\max }^{2}
$$

There are many parameters involved in the design of the detonation powerplant. Among these parameters, some are dynamic variables, some are constant numbers, some have a relatively big influence on the performance of the internal ballistics of the detonation powerplant while some are the secondary parameters which only have a little influence, some are independent from each other, and some have influence on one another with certain correlation among them.

Optimizing the design variables must target the independent variables which have the most influence on the performance of the device and can respond most sensitively. For three fit clearances and their influences on the work capacity of the detonation powerplant being investigated, the constraint conditions are the following: (1) Taking the setup space for the detonation powerplant and the structural strength of the parts into consideration, set the maximum air pressure as $p_{\max }=150 \mathrm{MPa}$. (2) The volume of the gunpowder room is not only related to the setup space of the detonation powerplant, but also closely related to the fit sizes of the slide cylinder, cartridge, and the fixed cylinder. On the basis of the results of parameter optimization design in early stage, set the volume of the gunpowder room as $1610 \mathrm{~mm}^{3} \leq V \leq 1645 \mathrm{~mm}^{3}$. (3) The fit clearance being too large or too small will affect the improving of the accuracy and consistency of the work capacity of the detonation powerplant. And it also has a direct influence on the frictional resistance and gas leakage of the device. According to Section 2, three fit clearances can be set as $0.02 \mathrm{~mm} \leq \delta_{1} \leq 0.05 \mathrm{~mm}, 0.03 \mathrm{~mm} \leq \delta_{2}, \delta_{3} \leq 0.07 \mathrm{~mm}$. (4) The most appropriate rising height of the weight is $H_{0}=$ $514.9 \mathrm{~mm}$. 
Above all, the objective function of the question about the optimization design of the detonation powerplant internal ballistics is

$$
\begin{array}{ll}
\min & \left|H\left(V, \delta_{1}, \delta_{2}, \delta_{3}\right)-H_{0}\right| \\
& p\left(V, \delta_{1}, \delta_{2}, \delta_{3}\right) \leq p_{\max } \\
& V \in[1610,1645] \\
& \delta_{1} \in[0.02,0.05] \\
& \delta_{2}, \delta_{3} \in[0.03,0.07] .
\end{array}
$$

The fitness function is

$$
\text { Fit }(f(x, y))= \begin{cases}H_{\max }-f(x, y) & f(x, y)<H_{\max } \\ 0 & f(x, y) \geq H_{\max }\end{cases}
$$

$H_{\max }$ is the maximum approximated value of $f(x, y)$ in the equation.

3.3. Implementation Process of Genetic Algorithm. The optimization design process of internal ballistics parameters with Genetic Algorithm of the detonation powerplant is shown in Figure 7.

By employing MATLAB program, optimal results of the detonation powerplant internal ballistics parameters are obtained according to the internal ballistics zero dimension mathematical model of the device and Genetic Algorithm. The size of the population has a direct effect on the convergence procedure and the efficiency of calculating. If the population is too large, it will increase the calculating time greatly; if the population is too small, the calculating process might stop when a regional optimal result is obtained [19]. The study focuses on the processing of the rising height of the weight and the maximal gas pressure, and the population chosen in this paper has 50 individuals. The length of chromosome depends on the precision of optimal results. The more precise optimal results are, the longer the chromosome will be. The length of the three chromosomes that represent the three fit clearances in this paper is 18, and the searching range is $0.02 \mathrm{~mm} \leq \delta_{1} \leq 0.05 \mathrm{~mm}, 0.03 \mathrm{~mm} \leq \delta_{2}, \delta_{3} \leq$ $0.07 \mathrm{~mm}$. The length of the chromosome that represents the volume of gunpowder room is 18 , and the searching range is $1610 \mathrm{~mm}^{3} \leq V \leq 1645 \mathrm{~mm}^{3}$. Maximum generation is the condition that determines when the Genetic Algorithm should be stopped. Usually, whether the algorithm should be stopped or not depends on the running conditions of algorithm, the convergence situation, and the quality of the result. The maximum generation in this paper is 800 . Parameters of optimization design of internal ballistics with Genetic Algorithm are shown in Table 2.

According to the optimal results of the Genetic Algorithm, when genetic revolution goes on to the 800th generation, the convergence is reached. So choose the first generation, the 380th generation, and the 800th generation of all the 800 generations as representatives, and the individuals of these generations are shown in Tables 3,4 , and 5, respectively.

Table 3 shows that individuals of the first generation are produced by the program randomly. Table 4 shows that when

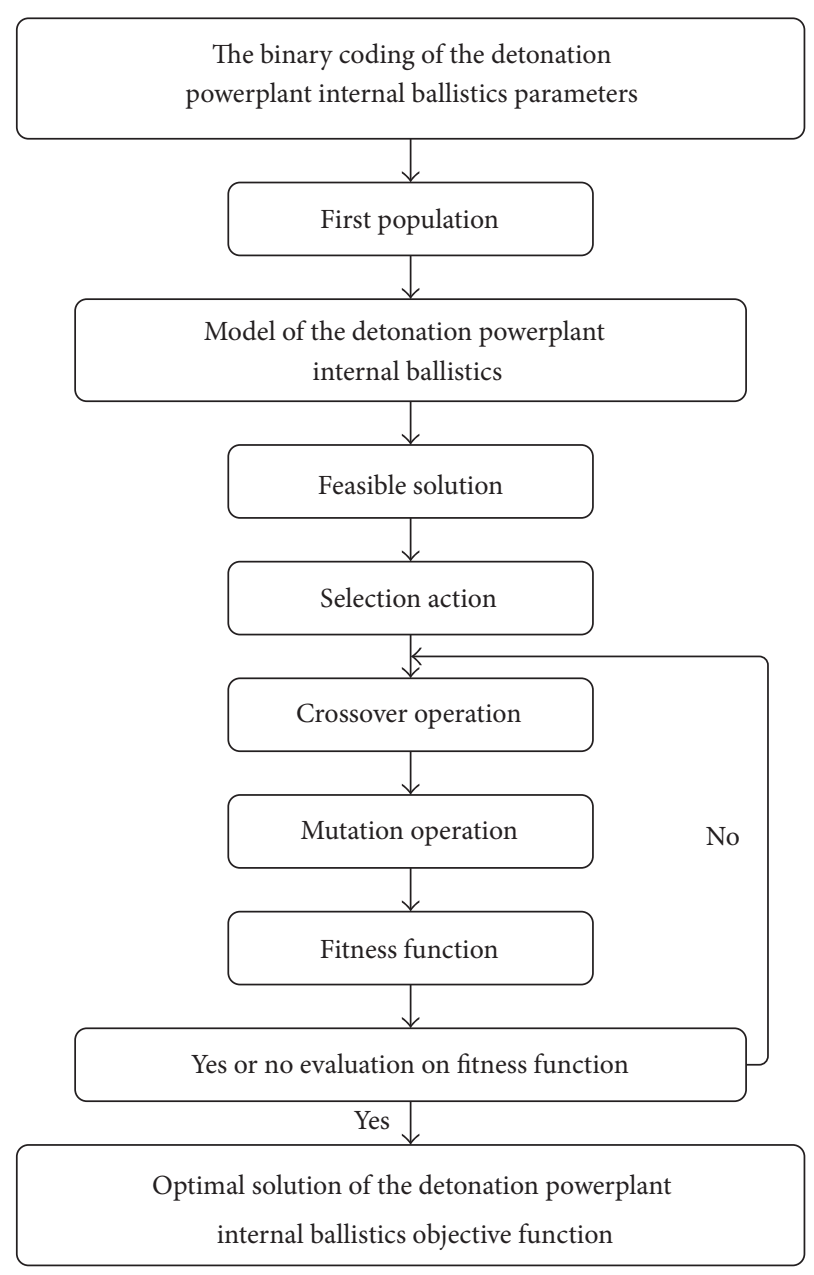

FIgURE 7: Flow chart of Genetic Algorithm of the detonation powerplant.

TABLE 2: Table of parameters of genetic algorithm.

\begin{tabular}{lc}
\hline Factors & Value \\
\hline The size of population & 50 \\
The length of chromosome & 18 \\
Maximum generation & 800 \\
Crossover probability & 0.7 \\
Mutation rate & 0.001 \\
Generation gap & 0.5 \\
\hline
\end{tabular}

the revolution reaches the 380 th generation, the individuals show the tendency of convergence, which is manifested in the table as the parameters dividing into six areas, with each area showing the convergence intensively. Table 5 shows that when the program evolves to the last generation, the population in the constraint situation reaches the best and the algorithm stops. The optimal results are $V=1629.55 \mathrm{~mm}^{3}, \delta_{1}=$ $0.034 \mathrm{~mm}, \delta_{2}=0.051 \mathrm{~mm}$, and $\delta_{3}=0.047 \mathrm{~mm}$. After the optimization, the optimal rising height of the weight that represents the work capacity of the detonation powerplant is 
TABLE 3: Results of the first generation.

\begin{tabular}{|c|c|c|c|c|c|c|}
\hline$N$ & $V / \mathrm{mm}^{3}$ & $\delta_{1} / \mathrm{mm}$ & $\delta_{2} / \mathrm{mm}$ & $\delta_{3} / \mathrm{mm}$ & $p_{\max } / \mathrm{MPa}$ & $H / \mathrm{mm}$ \\
\hline 1 & 1626.477 & 0.024 & 0.067 & 0.054 & 115.312 & 485.705 \\
\hline 2 & 1627.091 & 0.023 & 0.066 & 0.053 & 142.642 & 600.193 \\
\hline 3 & 1628.012 & 0.022 & 0.065 & 0.052 & 136.398 & 505.238 \\
\hline 4 & 1626.988 & 0.021 & 0.067 & 0.055 & 122.432 & 494.345 \\
\hline 5 & 1627.909 & 0.020 & 0.066 & 0.054 & 116.675 & 486.549 \\
\hline 6 & 1627.205 & 0.024 & 0.065 & 0.053 & 118.125 & 488.596 \\
\hline 7 & 1627.192 & 0.023 & 0.067 & 0.052 & 119.987 & 490.643 \\
\hline 8 & 1627.546 & 0.022 & 0.066 & 0.055 & 121.015 & 492.690 \\
\hline 9 & 1627.821 & 0.021 & 0.065 & 0.054 & 122.689 & 494.736 \\
\hline 10 & 1627.735 & 0.020 & 0.067 & 0.053 & 126.507 & 496.783 \\
\hline 11 & 1627.332 & 0.024 & 0.066 & 0.052 & 128.674 & 498.830 \\
\hline 12 & 1626.875 & 0.023 & 0.065 & 0.055 & 130.435 & 500.877 \\
\hline 13 & 1626.798 & 0.022 & 0.067 & 0.054 & 132.895 & 502.923 \\
\hline 14 & 1627.809 & 0.021 & 0.066 & 0.053 & 134.453 & 504.970 \\
\hline 15 & 1628.576 & 0.020 & 0.065 & 0.052 & 138.012 & 507.018 \\
\hline 16 & 1626.308 & 0.024 & 0.067 & 0.055 & 139.897 & 509.064 \\
\hline 17 & 1626.957 & 0.023 & 0.066 & 0.054 & 141.476 & 511.110 \\
\hline 18 & 1627.948 & 0.022 & 0.065 & 0.053 & 142.889 & 513.157 \\
\hline 19 & 1627.827 & 0.021 & 0.067 & 0.052 & 143.114 & 515.204 \\
\hline 20 & 1627.813 & 0.020 & 0.066 & 0.055 & 143.423 & 517.251 \\
\hline 21 & 1627.144 & 0.024 & 0.065 & 0.054 & 143.464 & 519.298 \\
\hline 22 & 1627.002 & 0.023 & 0.067 & 0.053 & 143.896 & 521.345 \\
\hline 23 & 1627.982 & 0.022 & 0.066 & 0.052 & 143.995 & 523.391 \\
\hline 24 & 1627.627 & 0.021 & 0.065 & 0.055 & 144.102 & 525.438 \\
\hline 25 & 1627.635 & 0.020 & 0.067 & 0.054 & 144.169 & 527.485 \\
\hline 26 & 1627.240 & 0.024 & 0.066 & 0.053 & 144.276 & 529.532 \\
\hline 27 & 1627.458 & 0.023 & 0.065 & 0.052 & 144.398 & 531.578 \\
\hline 28 & 1626.862 & 0.022 & 0.067 & 0.053 & 144.501 & 533.625 \\
\hline 29 & 1627.738 & 0.021 & 0.066 & 0.054 & 144.599 & 535.672 \\
\hline 30 & 1628.329 & 0.020 & 0.065 & 0.054 & 144.701 & 537.719 \\
\hline 31 & 1626.609 & 0.024 & 0.067 & 0.053 & 144.734 & 539.766 \\
\hline 32 & 1627.312 & 0.023 & 0.066 & 0.052 & 144.868 & 541.812 \\
\hline 33 & 1627.459 & 0.022 & 0.065 & 0.055 & 144.953 & 543.859 \\
\hline 34 & 1627.142 & 0.021 & 0.067 & 0.054 & 145.013 & 545.906 \\
\hline 35 & 1628.203 & 0.020 & 0.066 & 0.053 & 145.457 & 550.001 \\
\hline 36 & 1627.612 & 0.022 & 0.065 & 0.054 & 145.896 & 556.140 \\
\hline 37 & 1626.861 & 0.023 & 0.066 & 0.055 & 146.201 & 562.280 \\
\hline 38 & 1627.275 & 0.021 & 0.067 & 0.053 & 146.834 & 568.421 \\
\hline 39 & 1628.411 & 0.020 & 0.066 & 0.052 & 146.987 & 572.514 \\
\hline 40 & 1627.002 & 0.024 & 0.065 & 0.055 & 147.099 & 578.654 \\
\hline 41 & 1626.836 & 0.023 & 0.067 & 0.054 & 147.609 & 582.748 \\
\hline 42 & 1627.866 & 0.022 & 0.066 & 0.053 & 147.875 & 586.842 \\
\hline 43 & 1627.624 & 0.021 & 0.066 & 0.055 & 147.963 & 590.935 \\
\hline 44 & 1627.871 & 0.020 & 0.067 & 0.052 & 148.023 & 595.029 \\
\hline 45 & 1627.472 & 0.024 & 0.065 & 0.052 & 148.341 & 599.122 \\
\hline 46 & 1626.672 & 0.023 & 0.067 & 0.055 & 147.961 & 588.887 \\
\hline 47 & 1627.740 & 0.022 & 0.066 & 0.054 & 146.001 & 560.233 \\
\hline 48 & 1628.009 & 0.021 & 0.066 & 0.052 & 145.634 & 552.046 \\
\hline 49 & 1627.479 & 0.020 & 0.067 & 0.055 & 147.001 & 574.561 \\
\hline 50 & 1628.232 & 0.020 & 0.065 & 0.055 & 147.053 & 576.536 \\
\hline
\end{tabular}




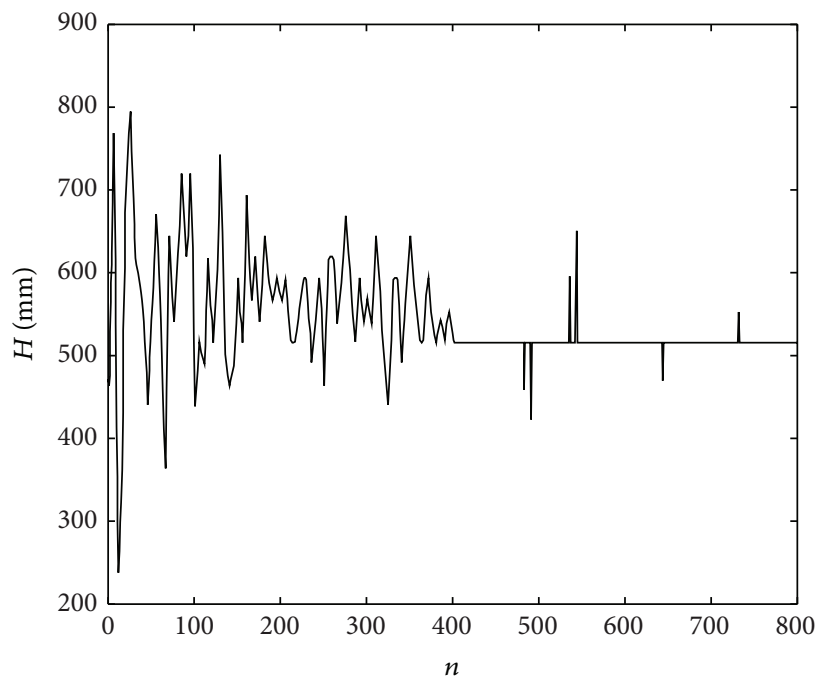

(a)

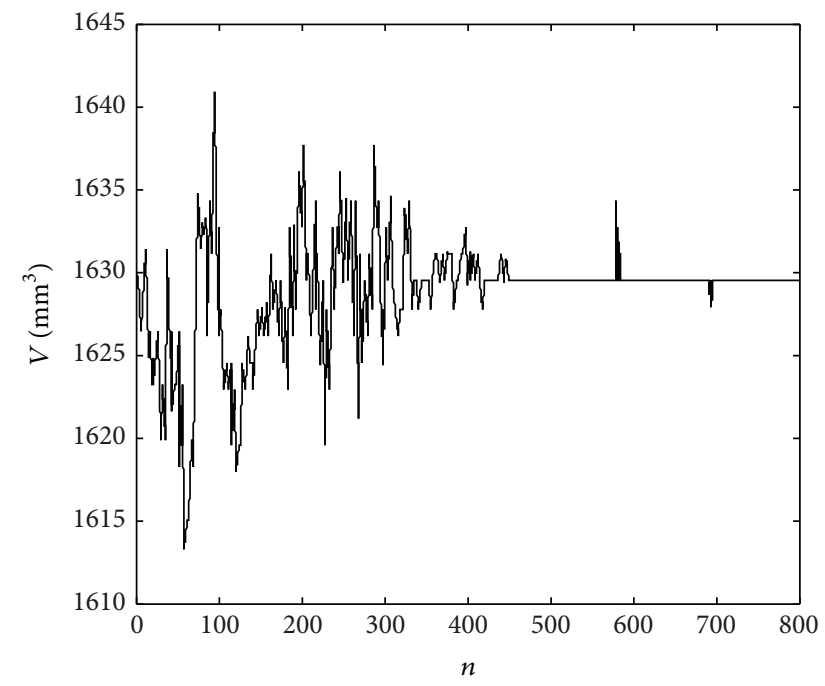

(b)

FIGURE 8: The maximum height convergence curve of weight (a) and the volume convergence curve of gunpowder chamber (b).

TABLE 4: Results of the 380th generation.

\begin{tabular}{|c|c|c|c|c|c|c|}
\hline$N$ & $V / \mathrm{mm}^{3}$ & $\delta_{1} / \mathrm{mm}$ & $\delta_{2} / \mathrm{mm}$ & $\delta_{3} / \mathrm{mm}$ & $p_{\max } / \mathrm{MPa}$ & $H / \mathrm{mm}$ \\
\hline $01-10$ & 1631.388 & 0.032 & 0.047 & 0.043 & 144.398 & 531.578 \\
\hline $11-18$ & 1631.286 & 0.032 & 0.048 & 0.043 & 143.896 & 521.345 \\
\hline $19-26$ & 1631.184 & 0.033 & 0.048 & 0.043 & 143.995 & 523.391 \\
\hline $27-34$ & 1631.081 & 0.033 & 0.049 & 0.044 & 144.169 & 527.485 \\
\hline $35-42$ & 1630.979 & 0.034 & 0.049 & 0.044 & 144.276 & 529.532 \\
\hline $43-50$ & 1630.774 & 0.034 & 0.050 & 0.044 & 144.102 & 525.438 \\
\hline
\end{tabular}

TABLE 5: Results of the 800th generation.

\begin{tabular}{lcccccc}
\hline$N$ & $V / \mathrm{mm}^{3}$ & $\delta_{1} / \mathrm{mm}$ & $\delta_{2} / \mathrm{mm}$ & $\delta_{3} / \mathrm{mm}$ & $p_{\max } / \mathrm{MPa}$ & $H / \mathrm{mm}$ \\
\hline $01-50$ & 1629.552 & 0.034 & 0.051 & 0.047 & 143.116 & 515.205 \\
\hline
\end{tabular}

$H=515.21 \mathrm{~mm}$. Convergences of the all the generations are shown in Figures 8 and 9.

It is shown in the convergence curve that the optimal design variable $V, \delta_{1}, \delta_{2}, \delta_{3}$, and the objective function $H$ vibrate violently in the early stage of Genetic Algorithm computing. With the increasing of iterations, the range of the vibration becomes smaller. When the iteration of the algorithm reaches 500, the algorithm finds the optimal results of the detonation powerplant internal ballistics parameters. In the solution procedure of the algorithm, vibrations will happen occasionally for the mutation operation, which will not influence the convergence of optimal results.

\section{Experiment on the Accuracy of Work Capacity of the Detonation Powerplant}

On the basis of the theoretical optimal parameters of fit clearances of the detonation powerplant obtained in Section 3.3, detonation powerplants illustrated in Figure 10 are made. (On the left is the mechanical part without gunpowder and electric igniters. On the right is the eight sets of assembled detonation powerplants.)

To test the accuracy of the work capability and consistency of the detonation powerplant, the evaluation device of work capacity is made. The device consisting of a baseboard, a weight, and two guide rods is depicted in Figure 11. The baseboard is a $10 \mathrm{~mm}$ thick steel plate, on which the detonation powerplant and guide rods are fixed; the guide rods are two $1000 \mathrm{~mm}$ long cylindrical rods which are $20 \mathrm{~mm}$ in diameter. The guide rods are fixed on the baseboard by thread connection whose axes are perpendicular to the surface of the baseboard. There are two graduated scales attached to the rods, indicating the length; the weight is $60 \mathrm{~kg}$. In the middle of the weight there are two through-holes which are $25 \mathrm{~mm}$ in diameter and the distance between the two holes is $120 \mathrm{~mm}$. The whole process of the work capacity test experiment is recorded by a high-speed camera. The results are shown in Figure 12. 


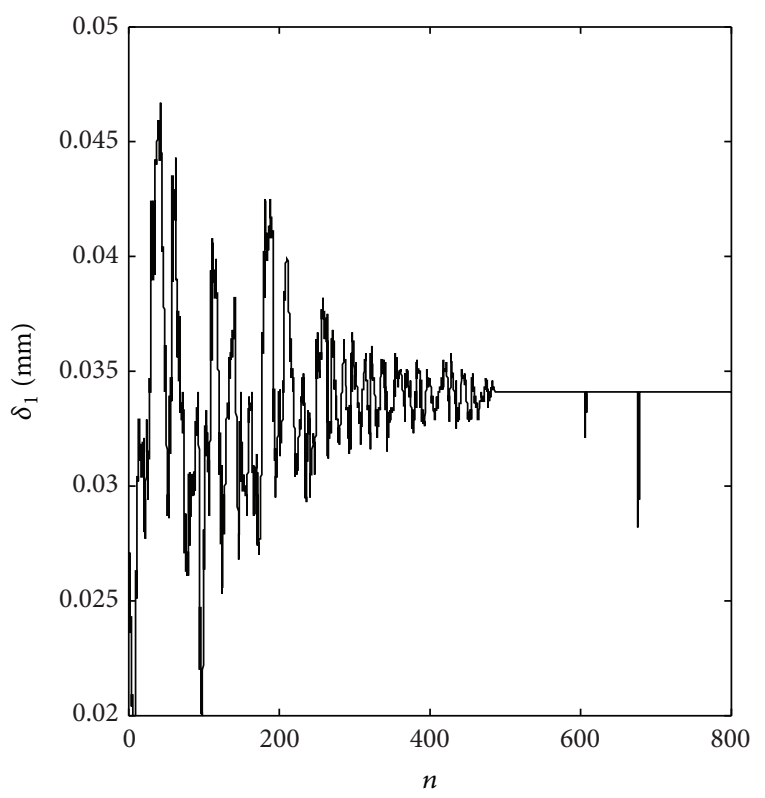

(a)

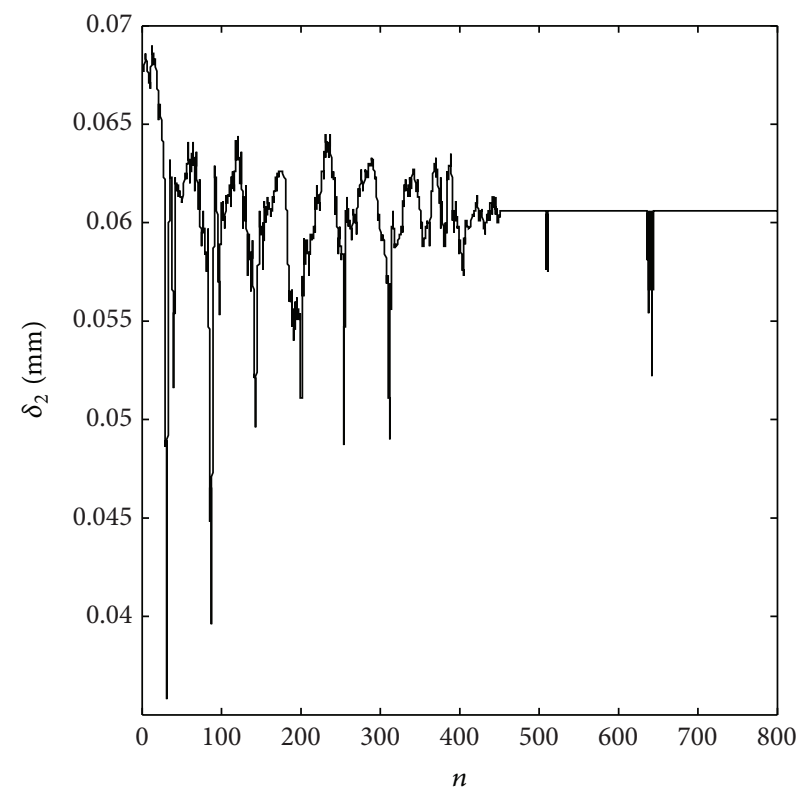

(b)

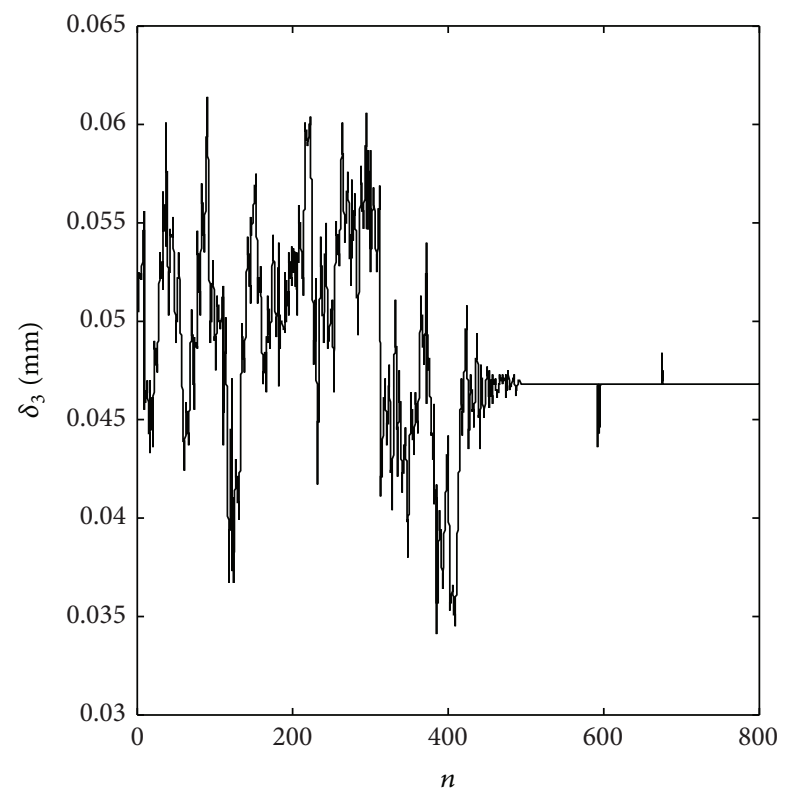

(c)

Figure 9: The convergence curve of $\delta_{1}(\mathrm{a}), \delta_{2}(\mathrm{~b})$, and $\delta_{3}(\mathrm{c})$.
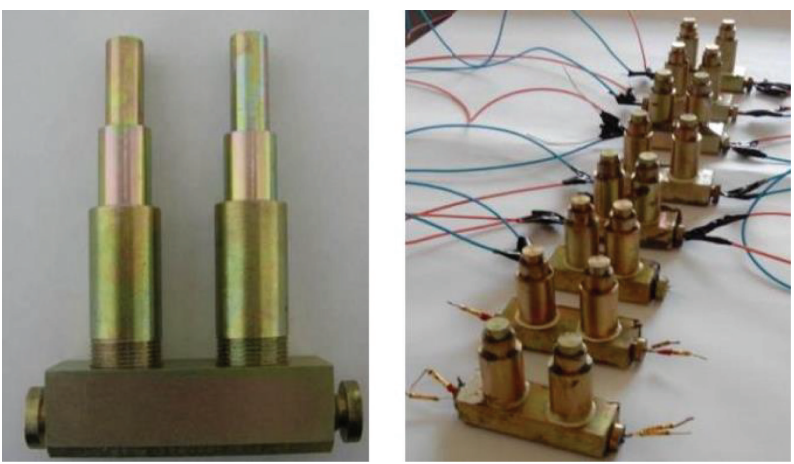

FIGURE 10: Detonation powerplants. 


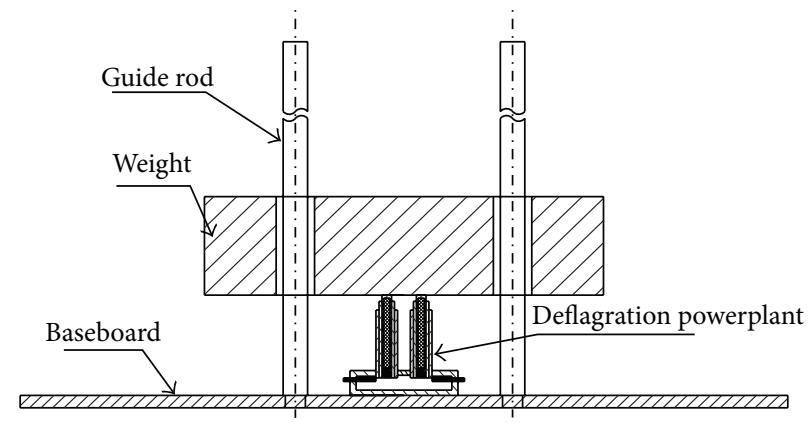

FIGURE 11: The evaluation device of the work capacity of the detonation powerplant.

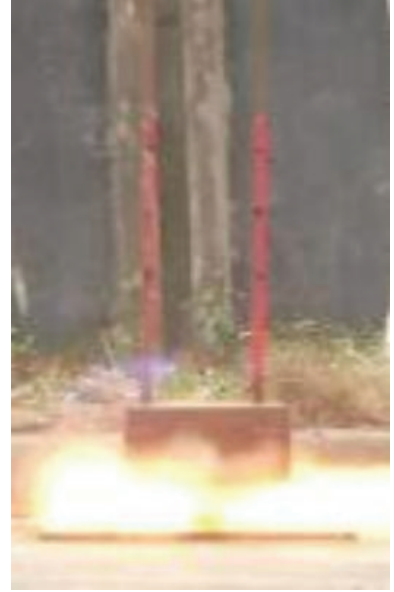

(a) Early stage of detonation

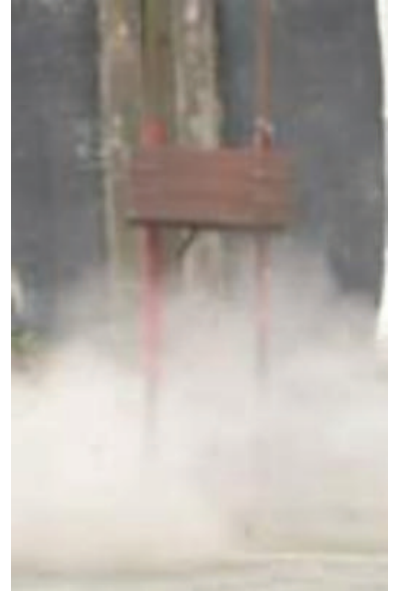

(b) Uplifted stage of weight

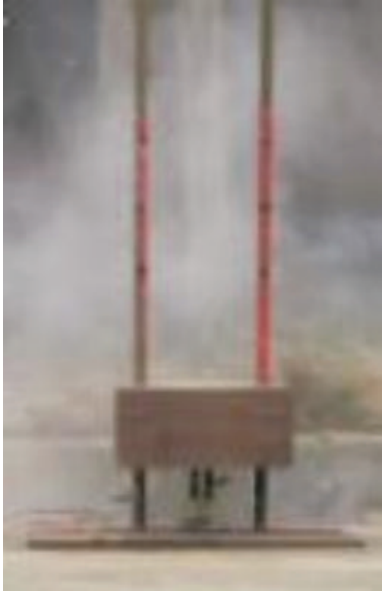

(c) Falling stage of weight

FIGURE 12: Power capability assessment experiment process of the detonation powerplant.

TABLE 6: Results of experiment on the accuracy of work capacity of the detonation powerplant.

\begin{tabular}{lcccccccc}
\hline$N$ & 1 & 2 & 3 & 4 & 5 & 6 & 7 & 8 \\
\hline$H / \mathrm{mm}$ & 510.3 & 511.4 & 509.6 & 512.1 & 511.2 & 510.3 & 511.4 & 505.6 \\
\hline
\end{tabular}

The requirements of materials, the high-level machining precision, and special eclectic igniters make the manufacture cost of the detonation powerplant very high. In order to reduce the research cost, this study tests the work capacity of the device under theoretical optimal parameters of fit clearances got from the Genetic Algorithm through the eight sets of experiment and LS-DYNA simulation of explosive and shock process of the device. The results of the experiment are displayed in Table 6, and the result of LS-DYNA simulation is shown in Figure 13.

Remove the deviated data from the eighth experiment and analyze and compute the datum as follows: The average value of results is $\bar{x}=\sum_{i}^{n} x_{i} / n=510.9 \mathrm{~mm}$; the range is $X=x_{\max }-x_{\min }=2.5 \mathrm{~mm}$; the relative error between the experimental average and the theoretical value is $\eta_{1}=$ $\left|\bar{x}-x_{t}\right| / x_{t} \times 100 \%=0.84 \%$; the relative error between the simulation value and the theoretical value is $\eta_{2}=\mid h-$ $x_{t} \mid / x_{t} \times 100 \%=0.49 \%$. There are reasonable errors between

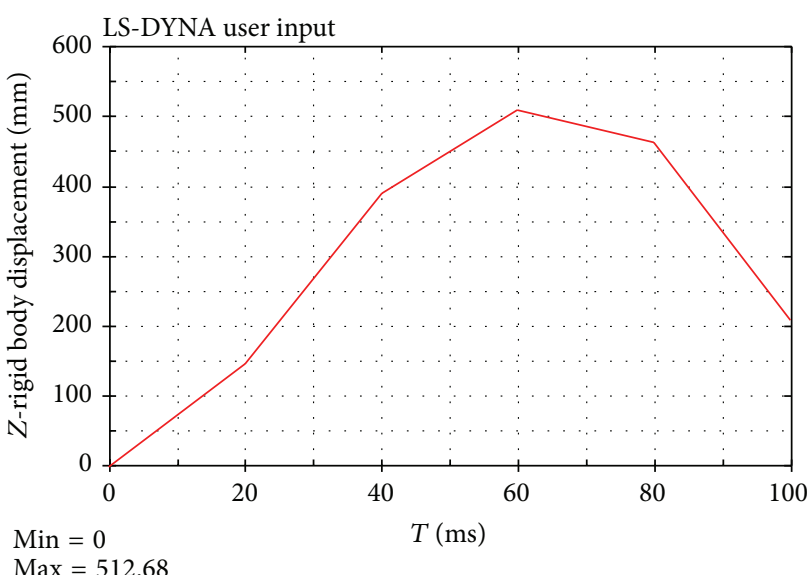

FIGURE 13: $\delta_{1}=0.034, \delta_{2}=0.051$, and $\delta_{3}=0.047 ; T-Z$ curve.

the experimental value and the theoretical value, as well as the simulation value and the theoretical value. And the experimental results have small fluctuation. At last, after the optimization, the work capacity of the detonation powerplant meets the technical indicator that the error needs to be less than $10 \%$. 


\section{Conclusions}

Conclusions as below are drawn on the basis of LS-DYNA simulation of the explosive and shock process of the detonation powerplant, optimal design of Genetic Algorithm, and related test experiments.

(1) By simulating the explosive and shock process of the detonation powerplant with LS-DYNA, the main factors that affect the accuracy of the work capacity of the device are found. They are the fit clearances between the outer wall of the cartridge and the inner wall of the slide cylinder, the outer wall of the slide cylinder and the lace of the fixed cylinder, and the lace of the slide cylinder and the inner wall of the fixed cylinder, and the reasonable range of these three fit clearances is figured out, which lays a foundation for further optimization design of the detonation powerplant.

(2) The internal ballistics zero dimension mathematical model of the detonation powerplant is used as the optimal design model of the device internal ballistics parameters in Genetic Algorithm and the objective function, optimization design variables, and restraint condition used in the study are appropriate. As a result, optimal fit clearances as expected are found.

(3) The device used in the detonation powerplant work capacity test experiment is simple and appropriate and satisfies the accuracy required in theory. And the work capacity of the detonation powerplant under the optimal fit clearances obtained from Genetic Algorithm is tested through experiment and LSDYNA simulation. And within an acceptable error range, the results from the experiment are consistent with the theoretical values of fit clearances, which satisfies the design goal.

In conclusion, the analysis method used in this paper is meaningful for further optimization design of the detonation powerplant in both theory and reality. Nowadays, it has been implied to the test flight of airliner made in China.

\section{Nomenclature}

$\Psi$ : The percentage of the gunpowder burned

$\Delta$ : Density of gunpowder installed

$\rho_{p}$ : Density of gunpowder

$\alpha$ : Gunpowder gas covolume which is 0.5

$Z$ : Relative thickness of the gunpowder burned

$\rho$ : Density of gas inside the device

$Q$ : Flow velocity of gas in vertical direction

A: Area of clearance axial section

$t$ : Independent variable time

$z:$ Independent variable displacement

$\mu_{1}$ : Burning speed coefficient which is 0.2

$n$ : Burning speed index which is 0.82
$I_{k}: \quad$ Total pressure impulse

E: Total energy

M: Mass of the weight

$H$ : Height of weight's rising

$\lambda, \chi$ : The shape, feature, and quantity of gunpowder

$l_{\Psi}: \quad$ Reduction diameter of gunpowder's free volume

$\varphi$ : Calculated coefficient of secondary work done by the device $\varphi=\varphi_{1}+\omega / 3 m$;

$\varphi_{1}=1.2$

$f: \quad$ Gunpowder force which is $310 \mathrm{~kJ} / \mathrm{kg}$

$f_{z}$ : Mass force per unit in vertical direction

$p: \quad$ Gas pressure inside the device

$W$ : Gravitational potential energy of the weight

q: Heat passed to unit mass air in unit time

$\eta$ : $\quad$ Relative air leakage flow

$y$ : Total air leakage

$\omega: \quad$ Mass of gunpowder installed

$v$ : Speed of cartridge

$l: \quad$ Displacement of cartridge

$k$ : $\quad$ Adiabatic coefficient which is 1.2

$m$ : Mass of equivalent mass entity

$e_{1}$ : $\quad$ Propellant web size which is 0.068

$S_{1}$ : Area of the cartridge axial section

$S_{2}$ : Area of the slide cylinder axial section

$g$ : $\quad$ Gravity coefficient

$v_{\text {max }}$ : Maximum value of the cartridge's speed

$E_{\max }:$ Maximum value of the cartridge's kinetic energy

$p_{0}: \quad$ Device start-up pressure $p_{0}=(m g+F)$. Device $F$ initiates resistance force which is the aerodynamic load applied on service door in flying.

\section{Competing Interests}

The authors declare that they have no competing interests.

\section{Acknowledgments}

The work described in this paper is financially supported by the China National Aviation Holding Company under Grant no. NJCX-RW-20100208. The authors would like to gratefully acknowledge this support.

\section{References}

[1] H. L. Lu and Y. Fei, Escape, Survival and Rescue in the Aircraft Accidents, National Defense Industry Press, Beijing, China, 2006.

[2] C. F. Fan, Y. H. Wang, R. Ma, M. J. Duan, and X. Chang, "The force state analysis of the service door on an airliner," Advanced Materials Research, vol. 798, pp. 325-327, 2013.

[3] J. A. Longridge, Internal Ballistics, Kessinger Pub Company, Whitefish, Mont, USA, 2008.

[4] L. Davis, Genetic Algorithms and Simulated Annealing, Pittman, London, UK, 1987. 
[5] D. E. Goldberg, Genetic Algorithms in Search, Optimization and Machine Learning, Addison-Wesley, Reading, Mass, USA, 1989.

[6] S. Forrest, "Genetic algorithms: principles of natural selection applied to computation," Science, vol. 261, no. 5123, pp. 872-878, 1993.

[7] S. Q. Shi, J. K. Kang, M. Wang et al., The Engineer Implication of ANSYS/LS-DYNA in Explosion and Shock, Architecture \& Building Press, Beijing, China, 2011.

[8] J. O. Hallquist, LS-DYNA Theoretical Manual, Livermore Software Technology Corporation, Livermore, Calif, USA, 1998.

[9] J. D. Reid, LS-DYNA Examples Manual, Livermore Software Technology Corporation, Livermore, Calif, USA, 1998.

[10] LSTC.LS-DYNA Keyword User's Manual, Livermore Software Technology Corporation, Livermore, Calif, USA, 2003.

[11] R. J. Muzzy and C. E. Wooldridge, "Internal ballistic considerations in hybrid rocket design," Journal of Spacecraft and Rockets, vol. 4, no. 2, pp. 255-262, 1967.

[12] J. Greig, J. Earnhart, N. Winsor et al., "Investigation of plasmaaugmented solid propellant interior ballistic processes," IEEE Transactions on Magnetics, vol. 29, no. 1, pp. 555-560.

[13] P. G. Baer and J. M. Frankle, "The simulation of interior ballistic performance of guns by digital computer program," Tech. Rep. BRLMR-1183, BRL, ARDC, Ballistic Research Laboratories, Aberdeen Proving Ground, Md, USA, 1962.

[14] S. Jaramaz, D. Micković, and P. Elek, "Two-phase flows in gun barrel: theoretical and experimental studies," International Journal of Multiphase Flow, vol. 37, no. 5, pp. 475-487, 2011.

[15] M. Sanford and T. A. DelGuidice, Energy Absorbing Countermass for Shoulder-Launched Rocket Weapon, NTIS, ADD019605, 2000.

[16] H. Miura, A. Matsuo, and Y. Nakamura, "Three-dimensional simulation of pressure fluctuation in a granular solid propellant chamber within an ignition stage," Propellants, Explosives, Pyrotechnics, vol. 36, no. 3, pp. 259-267, 2011.

[17] J. Nussbaum, P. Helluy, J.-M. Herard, and B. Baschung, "Multidimensional two-phase flow modeling applied to interior ballistics," Journal of Applied Mechanics, vol. 78, no. 5, Article ID 051016, 9 pages, 2011.

[18] L. G. Vulkov, "On the conservation laws of the compressible euler equations," Applicable Analysis, vol. 64, no. 3-4, pp. 255271, 1997.

[19] L. F. Ding, Z. W. Cheng, and Z. F. Chen, "Simulation and research on the control parameters of genetic algorithm," Science \& Technology Information, vol. 36, article 774, 2007. 


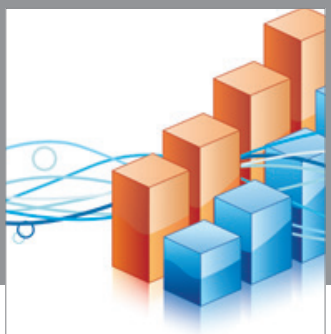

Advances in

Operations Research

vatem alat4

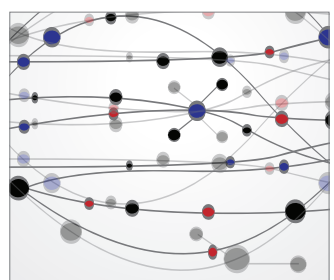

\section{The Scientific} World Journal
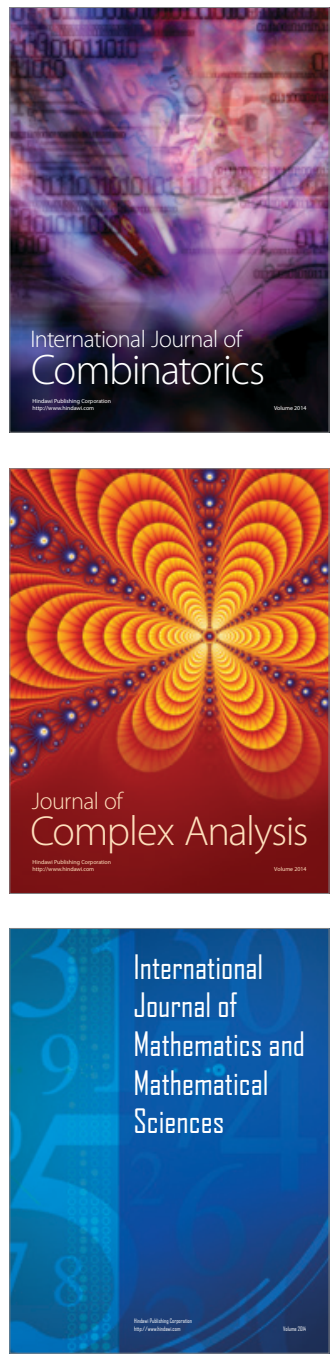
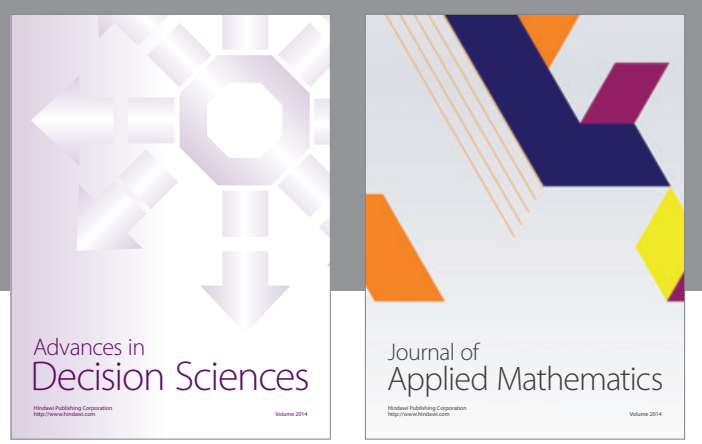

Algebra

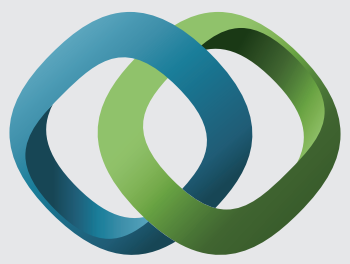

\section{Hindawi}

Submit your manuscripts at

http://www.hindawi.com
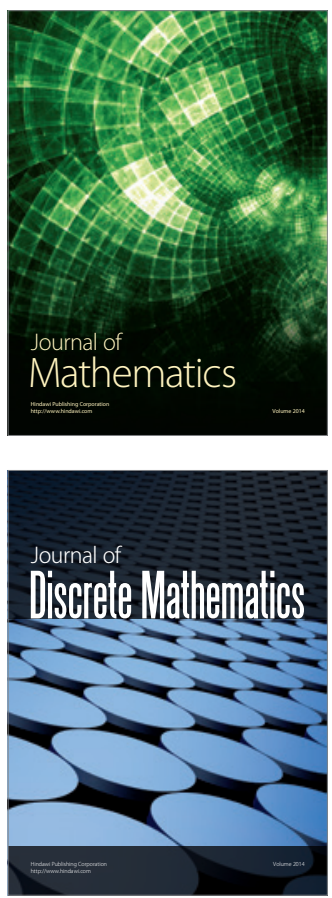

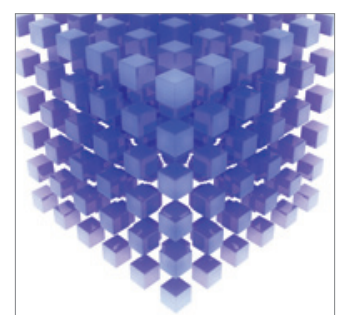

Mathematical Problems in Engineering
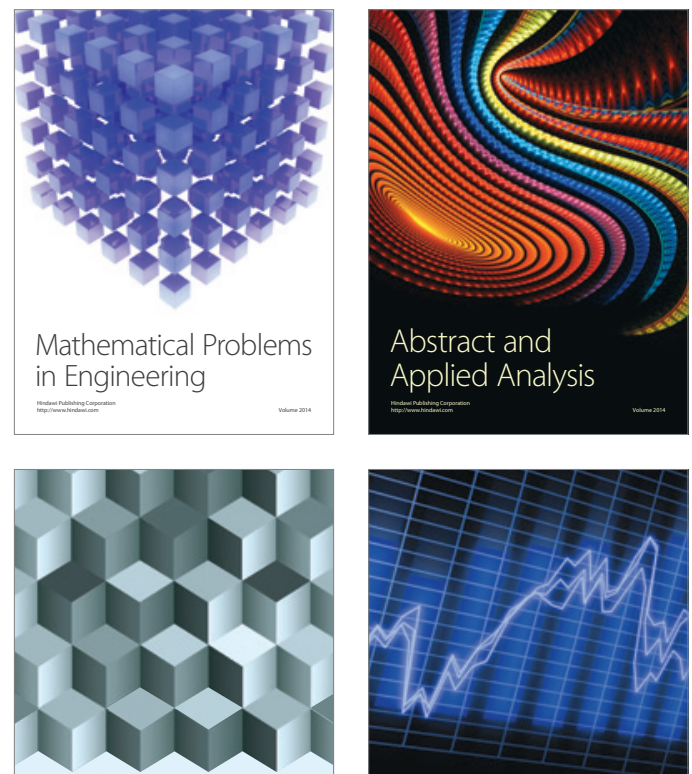

Journal of

Function Spaces

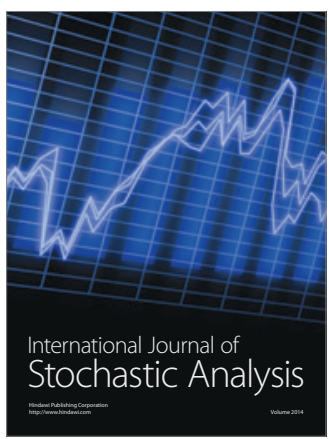

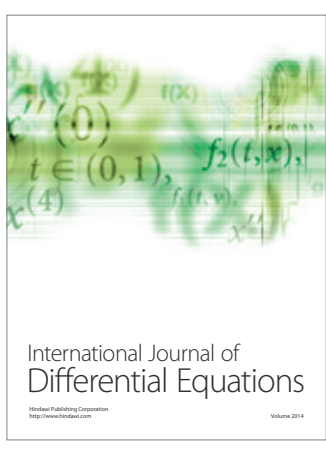
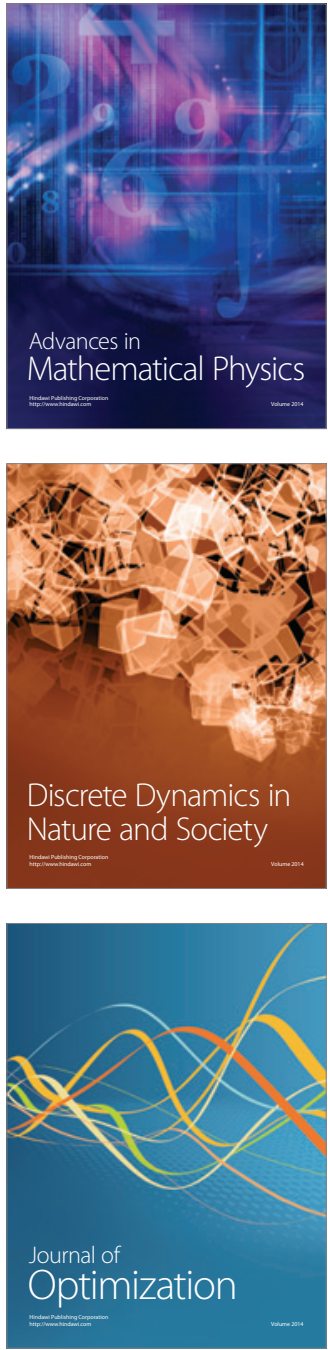